TP Periodica Polytechnica

61(2), pp. 244-255, 2017

https://doi.org/10.3311/PPci.8454

Creative Commons Attribution (i)

RESEARCH ARTICLE

\section{Development and Validation of Predictive Model to Describe the Growth of Concrete Water Tank Vulnerability with Time}

\author{
Amar Aliche ${ }^{1}$, Hocine Hammoum ${ }^{1 *}$, Karima Bouzelha ${ }^{1}$, \\ Naceur Eddine Hannachi ${ }^{1}$
}

Received 31 July 2015; Revised 08 March 2016; Accepted 02 June 2016

\begin{abstract}
In the field of civil engineering, concrete water tanks, considered as hydraulic structures, take a special place among constructions. These tanks subjected to harsh natural conditions and to hydrodynamic loads, age and deteriorate. In order to predict the degradation and ageing level that can occur in these structures, the concept of vulnerability to natural hazards, based on the assessment of vulnerability index $\left(I_{v}\right)$ is used. We develop in this paper a predictive model which describes the growth of tank vulnerability with time. This numerical model is built by using numerical analysis methods, where an approximate function $I_{V}(t)$ is developed in order to translate the evolution of the vulnerability at any time during the life cycle of a tank. As the vulnerability index of a tank is known only at certain ages of its life cycle, the approached function $I_{V}(t)$ is approximate by a finite element modelling on this known domain, but it is extrapolated by an exponential model in the unknown domain. To resolve the different equations developed in this work, Mat$l a b^{\circledR}$ software had been used. The predictive model obtained has been applied to tanks of Tizi Ouzou region (Northern Algeria), and results showed that it could simulate and predict well the vulnerability index.
\end{abstract}

\section{Keywords}

Vulnerability index, ageing, concrete tank, life cycle, finite element, exponential approach, predictive model

${ }^{1}$ Civil Engineering Department, University of Mouloud Mammeri, 15000 Tizi Ouzou, Algeria

*Corresponding author, e-mail: hammoum_hoc@yahoo.fr

\section{Introduction}

The Algerian heritage of drinking water storage tank has almost 40,000 tanks and is mostly built of reinforced concrete. The average age of the national heritage of concrete tanks is about forty years. The feedback from nearly half a century of management has highlighted a great disparity in the behaviour of these structures, expressed by several pathologies [1]. The lack of maintenance of these tanks, directly exposed to natural threats (snow, earthquakes, winds), accelerates the ageing process. In consideration to this, in recent years, civil engineering activity is repositioning primarily in the life cycle of existing structures operation rather than in the design and construction of new structures. Therefore, we note a great interest in the scientific community to risk analysis. Many methods have been developed by several authors intended to structure managers in order to assess the structural performance, to make risk analysis or programming maintenance actions for hydraulic structures, harbour structures and buildings. We mainly cite the reliability approach, the approach using physical models and expertise approach.

The reliability approach based on probabilistic analysis has its limitations when the data is in insufficient quantity and in poor quality. Probability calculations become quickly complicated or impossible and their validity becomes difficult to demonstrate. We are then in the presence of the concept of imprecise probabilities. The interested reader by further details can consult the reference [2]. This latter provides an overview on developments which involve imprecise probabilities for the solution of engineering problems. Evidence theory, probability bounds analysis with p-boxes, and fuzzy probabilities are discussed with emphasis on their key features and on their relationships to one another. In the case where the structure is badly known and where the available data are of poor quality, the deterministic method using physical models; which consists of a recalculation of the structure; is difficult to implement. So, the simplest way to assess the future development of damages is to examine the evolution laws of existing structures of same design that have similar mechanisms, based on the experience feedback. This method is known as the expert approach that will be discussed in this paper. 
Peyras et al. [3, 4] were interested in the development of diagnostic methods and risk analysis related to the ageing of dams, based on an expertise approach, by the modelling of ageing scenarios from the failure mode and effect analysis (FMEA) method. This qualitative method led to the determination of a dam criticality index. Serre et al. [5, 6] developed a geographic information system (GIS) with the intention of incorporating it with models for assessing levee performance. In this research, failure mechanisms were modelled and performance indicators were identified for each mechanism. Bouzelha et al. [7] proposed an assessment method of the vulnerability presumption of small dams to natural hazards by calculation of vulnerability index. A first GIS was developed as a tool for managers of hydraulic structures to make decisions. Boero et al. [8] have implemented a methodology for risk analysis applied to optimize the management of harbour structures. This qualitative method is performed to inventory exhaustively failure modes and rank them, using a risk indicator. In the building field, the most widely used method is developed by the Gruppo Nazionale per la Difesa dai Terremoti of the Italian Consiglio Nazionale delle Ricerche (CNR-GNDT), it evaluates the seismic vulnerability of buildings, determined as a normalized vulnerability index. It has been proposed for the first time by Benedetti et al. [9]. It has been generalized and several studies have been dedicated to the CNR-GNDT method, in some countries in South America, Europe and North Africa, such as Mansour et al. [10], Vicente et al. [11], Gent Franch et al. [12] and Bezzazi et al. [13]. In the field of storage tanks, which is the subject of our interest, Mathieu [14] at IRSTEA (formerly Cemagref) proposed, since the nineties, a method that aims to indicate structures which have a sensitive environment, an important strategic character and those with or without visual structural disorders of variable severity. Using a similar approach than Mathieu, Hammoum et al. [1] have proposed a new methodology for diagnosis and analysis of the vulnerability of concrete tanks, by determining a vulnerability index. This method is exposed in Section 3. Readers wishing for further details can consult the reference [1].

In studies shown above, we notice that the vulnerability index for some authors, the performance indicator and the criticality index or the risk indicator for other authors is evaluated at a given time $(\mathrm{t})$ of cycle life structure, corresponding to a moment when the inspection is done.

But, the manager must have a global view of the state of all structures in operation at every moment of their life cycle, in order to refine his schedule for priority action with time, for maintenance and repair, taking into account the significant budgetary constraints. For this, he should use a decision-making tool that allows him to predict the level of tanks vulnerability with time, without the need for an operation of investigation in the field, on a large scale, which would be costly of material, human and financial resources. Therefore to predict the vulnerability level of a tank with time we should develop a predictive model.
Predictive models have been used in civil engineering to study the lifetime of structures by the assessment of their performance or vulnerability. Shamir and Howard [15] developed predictive models to study the pipe break failures in urban water distribution systems and applied these results for making better maintenance decisions. Their major advantage is their simplicity. Two equations were used, one linear and one exponential to describe the break rate as a function of time. Andreou [16] developed a model for analysis of the deteriorating water mains at the individual pipe level with implications of future maintenance practices. In order to evaluate the effect of ageing in pipes, the baseline hazard function estimated in the model was approximated by a second degree polynomial with time. In the field of concrete structures, the performance of concrete with time can be described diagrammatically as in Fig. 1 [17]. A model which has the merit to be simple has been proposed by Tutti [18] for predicting the life service of reinforced steel adopted to describe the deterioration mechanism. In his model, the performance index is given in function of time, and a limit value of this index is reported on the diagram which allows deducing the life service of the structure. Mehta [19] considered reinforced concrete with discontinuous microcracks as the starting point of a holistic model of concrete deterioration. In his model, the influence of environmental factors results in the propagation of these micro-cracks until they become continuous. Therefore, crack growth (which depends on the fracture strength) accelerates the penetration of aggressive substances into the concrete which in turn activates a number of other mechanisms of deterioration. Using a similar approach, Basheer et al. [17] developed a macro-model for each mechanism of deterioration relating to the physical properties of concrete.

In the mind of what is already practiced in the civil engineering profession, our research aims to develop a predictive model for the vulnerability index, linked to ageing, based on a multicriteria method and using finite element method. This model must be easily accessible to engineers, easily put into practice with an easy learning for future users. This research is a part of $\mathrm{PhD}$ thesis of Science in Civil Engineering and represents the continuity of research conducted by Hammoum et al [1]. This work clearly fits into a practical environment of the engineering and expert profession, by the applicative character and the very practical proposals it suggests. 


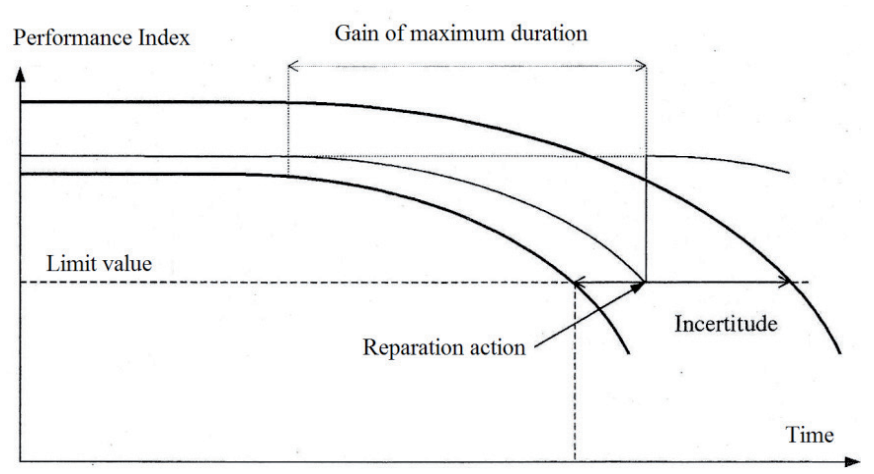

Fig. 1 Loss of performance with time

\section{Methodology}

If a same tank is inspected every year, after thirty years of investigation, the analysis will be representative, and that we might have enough data. However, we cannot wait so long, to obtain the behaviour law of vulnerability index linked to ageing of the tank. So, the approach used in this paper is, considering that the analysis by expertise is made on thirteen parameters (Table 1), we could take at the scale of Tizi Ouzou region more than thirty tanks which would share more than half of these parameters in common. Chosen tanks should have different ages, in order to simulate different ages on a life cycle of a tank type of Tizi Ouzou region, so that the analysis will be representative.

Section 3 contains a general description of the vulnerability index method, applied to tanks of Tizi Ouzou region. In section 4 , by using numerical analysis methods, we perform the vulnerability index as an approached function $I_{v}(t)$, known in some points, that is to say at different ages ( $\mathrm{t}$ ). In a first step, we will conduct a finite element modelling on a known domain (time interval) where the vulnerability index was quantified by the method described in section 3 , and which has given values known from expertise. In the second step, we will seek to model the vulnerability index evolution in the domain where this vulnerability index is unknown, by using an extrapolation model. Matlab ${ }^{\circledR}$ software [20] had been used to resolve the different equations developed in this research. Matlab is a highlevel language specially designed for dealing with matrices, making it particularly suitable for programming the numerical methods. Section 5 is dedicated to the validation of the predictive model. Finally, the main conclusions and the lessons learnt from this work are given in section 6 .

\section{Assessment method of vulnerability index $I_{v}$ 3.1 Exposed of the method}

In Algeria, up to now, there is no standardized or formalized methodology that allows us to analyze the state of vulnerability of a concrete tank. At the stage of preliminary studies or rapid diagnosis, when there is no sufficient data on the tank, the risk analysis can be performed by pure expertise. This analysis uses visual inspection and based only on the knowledge and the feedback from experts. We expose in this section the method of vulnerability index for concrete tanks to natural hazards developed by Hammoum et al. [1]. The calculation of this index involves thirteen (13) influential parameters for three types of analysis (environmental, structural and functional) which are summarized in Table 1.

Each of the thirteen parameters is rated by an elementary score $\left(\mathrm{N}_{\mathrm{e} i}\right)$. The selected scoring principle corresponding to the criteria amplification scores is based on the increase of vulnerability risk. Each elementary score is assigned by a weighting coefficient $\left(\mathrm{P}_{\mathrm{i}}\right)$. The elementary score $\left(\mathrm{N}_{\mathrm{ei}}\right)$ of each parameter is between 1 and 4: 1 is the ideal situation and 4 is the critical one. The same approach is used for weighting coefficient $\left(\mathrm{P}_{\mathrm{i}}\right)$ whose values vary from 1 to $4: 1$ for a minimum penalty parameter and 4 for a maximum penalty. A large assessment scale would require more finesse in the analysis, which may give rise to controversy within the same experts group who would have to analyze the same defect or pathology. Therefore, an analysis of an important number of values causes problems of overlapping qualitative levels. The IRSTEA experience in hydraulic structures damage assessment showed that an analysis on 4 values is well adapted to fast diagnosis and avoids a divergence between experts analysis [14]. It is for these listed reasons, that we have adopted a qualitative analysis based on four values which give the failure and degradation state. The partial score of a parameter is then obtained by the product $\left(\mathrm{N}_{\mathrm{ei}} . \mathrm{P}_{\mathrm{i}}\right)$ and the vulnerability index $I_{V}$ is expressed as the sum of partial scores of the different parameters:

$$
\mathrm{I}_{\mathrm{v}}=\sum_{\mathrm{i}=1}^{13} \mathrm{~N}_{\mathrm{ei}} \cdot \mathrm{P}_{\mathrm{i}}
$$

Table 1 List of analysis parameters

\begin{tabular}{ccc}
\hline Analysis type & $\mathbf{N}^{\circ}$ & Definition of the parameters \\
\hline \multirow{2}{*}{$\begin{array}{c}\text { Environmental } \\
\text { analysis }\end{array}$} & 1 & Tank location \\
& 2 & Seismic zone \\
& 4 & Soil type \\
& 5 & Snow zone \\
& 6 & Wind zone \\
Structural & 7 & Structure type \\
analysis & 8 & Foundation type \\
& 9 & Sealing walls \\
& 10 & Sealing cover \\
& 11 & Apparent defects \\
Functional & 12 & Tank role \\
analysis & 13 & Tank importance \\
& & Maintenance frequency
\end{tabular}

For a given criterion, a grid of evolution of partial score $\left(\mathrm{N}_{\mathrm{ei}} \mathrm{P}_{\mathrm{i}}\right)$ is constructed, taking into account all possible scenarios. Results are shown in Table 2. 
Table 2 Partial score matrix evaluation of one parameter

\begin{tabular}{|c|c|c|c|c|c|}
\hline & & \multicolumn{4}{|c|}{ Elementary score $\mathbf{N}_{\mathrm{e} i}$} \\
\hline \multirow{5}{*}{ 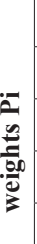 } & & 1 & 2 & 3 & 4 \\
\hline & 1 & 1 & 2 & 3 & 4 \\
\hline & 2 & 2 & 4 & 6 & 8 \\
\hline & 3 & 3 & 6 & 9 & 12 \\
\hline & 4 & 4 & 8 & 12 & 16 \\
\hline
\end{tabular}

Considering all the thirteen analysis criteria listed above, the following classification, divided into four levels of vulnerability is proposed.

- The green level $\left(13 \leq \mathrm{I}_{\mathrm{V}} \leq 49\right)$ : The tank is not appraised vulnerable. The structure presents a good behaviour to natural hazards and it doesn't require special attention after its entering service. Only regular interventions are needed.

- $\quad$ The orange level $1\left(49 \leq \mathrm{I}_{\mathrm{v}} \leq 87\right)$ : The behaviour of tanks to natural hazards is good enough. The tank is moderately vulnerable.

- $\quad$ The orange level $2\left(87 \leq \mathrm{I}_{\mathrm{V}} \leq 136\right)$ : The tank has a low behaviour to natural hazards. It is fairly highly vulnerable.

- The red level $\left(136 \leq \mathrm{I}_{\mathrm{v}} \leq 196\right)$ : The tank has a very low behaviour to natural hazards. It is very highly vulnerable. Therefore, the tank must be decommissioned or immediately put in circumstances of restricting use.

\subsection{Application to concrete tanks of Tizi Ouzou area}

The exposed method in the previous section has been successfully tested to 42 circular concrete tanks in Tizi Ouzou region. This area is classified zone of medium seismicity by the Algerian seismic code [21]. According to the Algerian Snow and Wind code [22], the area is classed as snow zone (A) and wind zone (1). The vulnerability index $I_{v}$ is determined, for each tank, from technical forms which we performed and filled during our investigation. We give in Table 3, as an example, the assessment of vulnerability index of Touares tank (Fig. 2) commissioned in 1965, located in Mirabeau (Tizi Ouzou, Algeria).

By analogous process, we calculated for each tank the vulnerability index obtained at the day of inspection, and the vulnerability index simulated at the day of its commissioning.

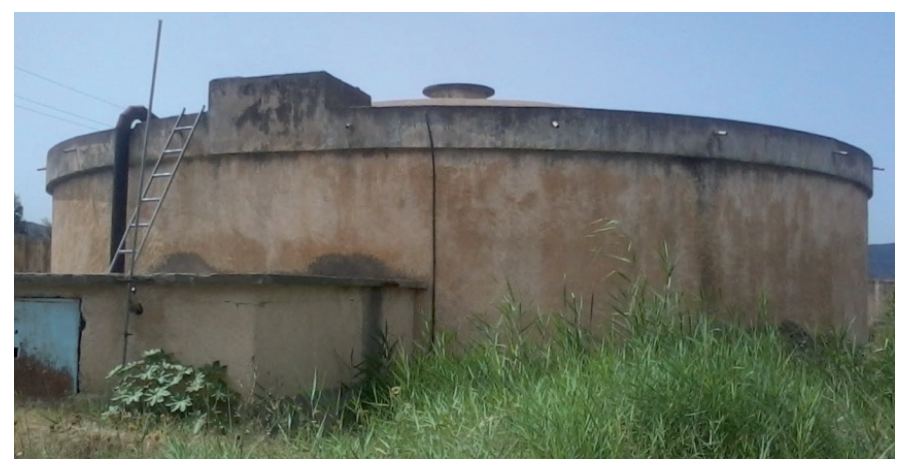

Fig. 2 General view of Touares tank

Results of these calculations are presented in Appendix. Through these results, we show that the vulnerability index $I_{v}$ evolves during the life cycle of a tank. Thus, if we consider that $\mathrm{I}_{\mathrm{v} 0}$ is the vulnerability index at commissioning, at the inspection day, corresponding to the time $\left(\mathrm{t}_{\mathrm{i}}\right)$ of its life cycle, this vulnerability index becomes $\mathrm{I}_{\mathrm{Vi}}$ such as $\mathrm{I}_{\mathrm{Vi}}>\mathrm{I}_{\mathrm{v} 0}$. So that its degradation state and/or ageing, reached with time, will make it more vulnerable to natural hazards.

Table 3 Vulnerability index assessment of Touares tank

\begin{tabular}{|c|c|c|c|c|c|c|c|}
\hline Analysis type & Elementary parameter & Scoring Criteria & $\mathbf{N}_{\mathrm{ei}}$ & Weighting parameter & Scoring Criteria & $\mathbf{P i}$ & $\mathbf{N}_{\mathrm{ei}} \cdot \mathbf{P}_{\mathrm{i}}$ \\
\hline \multirow{8}{*}{$\begin{array}{l}\text { Environmen- } \\
\text { tal }\end{array}$} & Tank location & mountain & 1.00 & Hydraulic parameter & Centre northern band & 3.00 & 3.00 \\
\hline & Seismic zone & Zone IIa & 2.00 & Implantation site & Urban area & 4.00 & 8.00 \\
\hline & Soil type & Loose soil & 3.00 & Site Effect & Risk of sliding & 4.00 & 12.00 \\
\hline & Snow zone & Zone A & 4.00 & Roofing form & Vault & 1.00 & 4.00 \\
\hline & \multirow{4}{*}{ Wind zone } & \multirow{4}{*}{ Zone I } & \multirow{4}{*}{2.00} & Height & $\mathrm{Ph}=0.75$ & \multirow{4}{*}{2.75} & \multirow{4}{*}{5.50} \\
\hline & & & & Land category & $\mathrm{Pc}=0.50$ & & \\
\hline & & & & Topographic site & $\mathrm{Pt}=0.75$ & & \\
\hline & & & & Surface state & $\mathrm{Ps}=0.75$ & & \\
\hline \multirow{5}{*}{ Structural } & Type of tank & On ground & 3.00 & Material & Reinforced concrete & 3.00 & 9.00 \\
\hline & Foundation type & General raft & 2.00 & Settlement state & No apparent & 1.00 & 2.00 \\
\hline & Sealing walls & Classe B & 2.00 & Seal State & Moderately satisfactory & 3.00 & 6.00 \\
\hline & Cover Type & Sealing by coating & 2.00 & Seal State & Enough satisfactory & 2.00 & 4.00 \\
\hline & Gravity index & Level 3 & 3.00 & Age of the tank & 49 years & 4.00 & 12.00 \\
\hline \multirow{4}{*}{ Functional } & Tank role & Distribution & 2.00 & Tank accessibility & By paved road & 1.00 & 2.00 \\
\hline & Importance of tank & For buildings (Group 1B) & 3.00 & Capacity of the tank & Capacity : $1000 \mathrm{~m}^{3}$ & 2.00 & 6.00 \\
\hline & Maintenance frequency & Annual & 4.00 & & & 4.00 & 4.00 \\
\hline & & & \multicolumn{4}{|c|}{ Vulnerability Index $I_{v}$} & 77.50 \\
\hline
\end{tabular}


Table 4 Evolution of the vulnerability index variation with time of a tank type

\begin{tabular}{|c|c|c|c|c|c|c|c|}
\hline $\mathbf{N}^{\circ}$ & Place called & Year of commissioning & Year of expertise & Age of the tank $\left(t_{i}\right)$ & $\mathbf{I}_{\mathrm{v}_{0}}$ & $\mathbf{I}_{\mathrm{vi}}$ & $\Delta \mathbf{I}_{\mathrm{vi}}$ \\
\hline 01 & Taghanimth & 2014 & 2014 & 0 & 47.50 & 47.50 & 0.00 \\
\hline 02 & Sidi Namane $\mathrm{SR}_{2}$ & 2012 & 2014 & 2 & 53.50 & 54.50 & 1.00 \\
\hline 03 & Mouldiouane Zone & 2010 & 2014 & 4 & 49.50 & 51.50 & 2.00 \\
\hline 04 & Megdoule 1 & 2008 & 2014 & 6 & 54.00 & 56.50 & 2.50 \\
\hline 05 & Taksebt & 2000 & 2010 & 10 & 43.00 & 48.50 & 5.50 \\
\hline 06 & Sidi Namane $\mathrm{SR}_{1}$ & 1999 & 2014 & 15 & 53.50 & 59.50 & 6.00 \\
\hline 07 & Behalil 1 & 1996 & 2014 & 18 & 46.00 & 53.00 & 7.00 \\
\hline 08 & Kaf Laagab & 1988 & 2014 & 26 & 56.00 & 65.00 & 9.00 \\
\hline 09 & Tighilt Tiguerfiouine & 1985 & 2014 & 29 & 56.00 & 66.00 & 10.00 \\
\hline 10 & Herrouka 2 & 1984 & 2014 & 30 & 46.00 & 56.50 & 10.50 \\
\hline 11 & Touares 2 & 1980 & 2014 & 34 & 61.00 & 72.00 & 11.00 \\
\hline 12 & Taghanimth & 1972 & 2010 & 38 & 47.50 & 60.50 & 13.00 \\
\hline 13 & Mekla Chef-Lieu SR & 1975 & 2014 & 39 & 50.50 & 64.00 & 13.50 \\
\hline 14 & Herrouka 1 & 1972 & 2014 & 42 & 48.50 & 63.50 & 15.00 \\
\hline 15 & Touares 1 & 1965 & 2014 & 49 & 60.50 & 77.50 & 17.00 \\
\hline
\end{tabular}

\section{Modelling of vulnerability index $I_{v}(t)$ in time}

We have seen, in the previous section, that a tank could have several vulnerability index $\mathrm{I}_{\mathrm{v}}$, during its life cycle. This leads us to think of building an approximate function $I_{v}(t)$ which translates the vulnerability index evolution linked to ageing of these structures in time. By relying on numerical analysis methods, we will consider that the vulnerability index function is known at some points, that is to say, at different ages. Since each tank has a vulnerability index $\mathrm{I}_{\mathrm{v} 0}$ different from another at its commissioning (see Appendix), we must build an approximate function $\Delta \mathrm{I}_{\mathrm{v}}(\mathrm{t})$, for tanks of Tizi Ouzou region, which represents the variation in the vulnerability index between the time of commissioning $\mathrm{t}_{0}$ and a time $\mathrm{t}_{\mathrm{i}}$. Among tanks inspected in Tizi Ouzou (Appendix), we selected tanks that share in common more than half of the thirteen analysis parameters shown in Table 1, but having different ages, in order to simulate the evolution of ageing in the life cycle of a tank type of Tizi Ouzou. The idea is to calculate for each selected tank, the variation of the vulnerability index $\Delta \mathrm{I}_{\mathrm{Vi}}$ at time $\mathrm{t}_{\mathrm{i}}$ (Table 4) with the following relation (2).

$$
\Delta \mathrm{I}_{\mathrm{vi}}=\mathrm{I}_{\mathrm{vi}}-\mathrm{I}_{\mathrm{v} 0}
$$

\subsection{Evolution of $\Delta \mathrm{I}_{\mathrm{v}}(\mathrm{t})$ in the known domain}

\subsubsection{Approach by nodal approximation}

In this section, we will see that we can approximate this unknown function of the vulnerability index linked to ageing by an approached function $\Delta \mathrm{I}_{\mathrm{v}}(\mathrm{t})$, over the study domain $\mathrm{t}$ $\epsilon[0,49]$, built on the basis of polynomial functions, linearly independent [23], as follows.

$$
\Delta \mathrm{I}_{\mathrm{v}}(\mathrm{t})=\alpha_{1}+\alpha_{2} \mathrm{t}+\alpha_{3} \mathrm{t}^{2}+\ldots+\alpha_{\mathrm{n}} \mathrm{t}^{\mathrm{n}-1}
$$

We define in Table 5, the geometry of the study domain. The nodal approximation on the domain $t \in[0,49]$ involves all the nodal variables attached to nodes on the concerned domain and on the border, for a total of 15 nodes. This leads us to write a polynomial of degree 14 in the following form:

$$
\Delta \mathrm{I}_{\mathrm{v}}(\mathrm{t})=\alpha_{1}+\alpha_{2} \mathrm{t}+\ldots+\alpha_{14} \mathrm{t}^{13}+\alpha_{15} \mathrm{t}^{14}
$$

That we can write in matrix form as follows:

$$
\Delta \mathrm{I}_{\mathrm{v}}(\mathrm{t})=<1, \mathrm{t}, \ldots ., \mathrm{t}^{13}, \mathrm{t}^{14}>\left\{\begin{array}{l}
\alpha_{1} \\
\alpha_{2} \\
\cdot \\
\cdot \\
\cdot \\
\alpha_{14} \\
\alpha_{15}
\end{array}\right\}=<\mathrm{P}(\mathrm{t})>\{\alpha\}
$$

$<>$ and \{\} mean respectively a line vector and a column vector. Coefficients $\alpha_{1}, \alpha_{2}, \ldots . \alpha_{15}$ are the parameters of the approximation. The approximated function $\Delta \mathrm{I}_{\mathrm{v}}(\mathrm{t})$ coincides with the exact values $\Delta \mathrm{I}_{\mathrm{Vi}}$ at the 15 points $\mathrm{t}_{\mathrm{i}}$ called nodes.

We can describe the domain $t \in[0,49]$ in a matrix form as given in equation (6).

Or more compactly:

$$
[\mathrm{A}] \cdot\{\alpha\}=\left\{\Delta \mathrm{I}_{\mathrm{v}}\right\}
$$

Then we deduce:

$$
\{\alpha\}=[\mathrm{A}]^{-1} \cdot\left\{\Delta \mathrm{I}_{\mathrm{v}}\right\}
$$

Values of nodal approximation parameters are given in Table 6. 


$\left[\begin{array}{ccccccc}1 & \mathrm{t}_{1} & \mathrm{t}_{1}^{2} & . & . & . & \mathrm{t}_{1}^{14} \\ 1 & \mathrm{t}_{2} & \mathrm{t}_{2}^{2} & . & . & . & \mathrm{t}_{2}^{14} \\ 1 & \mathrm{t}_{3} & \mathrm{t}_{3}^{2} & . & . & . & \mathrm{t}_{3}^{14} \\ 1 & \mathrm{t}_{4} & \mathrm{t}_{4}^{2} & . & . & . & \mathrm{t}_{4}^{14} \\ 1 & \mathrm{t}_{5} & \mathrm{t}_{5}^{2} & . & . & . & \mathrm{t}_{5}^{14} \\ 1 & \mathrm{t}_{6} & \mathrm{t}_{6}^{2} & . & . & . & \mathrm{t}_{6}^{14} \\ 1 & \mathrm{t}_{7} & \mathrm{t}_{7}^{2} & . & . & . & \mathrm{t}_{7}^{14} \\ 1 & \mathrm{t}_{8} & \mathrm{t}_{8}^{2} & . & . & . & \mathrm{t}_{8}^{14} \\ 1 & \mathrm{t}_{9} & \mathrm{t}_{9}^{2} & . & . & . & \mathrm{t}_{9}^{14} \\ 1 & \mathrm{t}_{10} & \mathrm{t}_{10}^{2} & . & . & . & \mathrm{t}_{10}^{14} \\ 1 & \mathrm{t}_{11} & \mathrm{t}_{11}^{2} & . & . & . & \mathrm{t}_{11}^{14} \\ 1 & \mathrm{t}_{12} & \mathrm{t}_{12}^{2} & . & . & . & \mathrm{t}_{12}^{14} \\ 1 & \mathrm{t}_{13} & \mathrm{t}_{13}^{2} & . & . & . & \mathrm{t}_{13}^{14} \\ 1 & \mathrm{t}_{14} & \mathrm{t}_{14}^{2} & . & . & . & \mathrm{t}_{14}^{14}\end{array}\right]\left\{\begin{array}{l}\alpha_{1} \\ \alpha_{2} \\ \alpha_{3} \\ \alpha_{4} \\ \alpha_{5} \\ \alpha_{6} \\ \alpha_{7} \\ \alpha_{8} \\ \alpha_{9} \\ \alpha_{10} \\ \alpha_{11} \\ \alpha_{12} \\ \alpha_{13} \\ \alpha_{14} \\ \alpha_{15}\end{array}\right\}=\left\{\begin{array}{l}\Delta \mathrm{I}_{\mathrm{v} 1} \\ \Delta \mathrm{I}_{\mathrm{V} 2} \\ \Delta \mathrm{I}_{\mathrm{V} 3} \\ \Delta \mathrm{I}_{\mathrm{V} 4} \\ \Delta \mathrm{I}_{\mathrm{v} 5} \\ \Delta \mathrm{I}_{\mathrm{V} 6} \\ \Delta \mathrm{I}_{\mathrm{V} 7} \\ \Delta \mathrm{I}_{\mathrm{V} 8} \\ \Delta \mathrm{I}_{\mathrm{V} 9} \\ \Delta \mathrm{I}_{\mathrm{V} 10} \\ \Delta \mathrm{I}_{\mathrm{V} 11} \\ \Delta \mathrm{I}_{\mathrm{v} 12} \\ \Delta \mathrm{I}_{\mathrm{V} 13} \\ \Delta \mathrm{I}_{\mathrm{V} 14} \\ \Delta \mathrm{I}_{\mathrm{v} 15}\end{array}\right\}$

(8)

Table 5 Identification of the whole domain

\begin{tabular}{|c|c|c|c|}
\hline Whole domain & Nodes & nodal coordinates (years) & $\Delta \mathbf{I}_{\mathrm{Vi}}$ \\
\hline & 1 & 0 & 0.00 \\
\hline & 2 & 2 & 1.00 \\
\hline & 3 & 4 & 2.00 \\
\hline & 4 & 6 & 2.50 \\
\hline & 5 & 10 & 5.50 \\
\hline & 6 & 15 & 6.00 \\
\hline & 7 & 18 & 7.00 \\
\hline \multirow[t]{8}{*}{$0<\mathrm{t}<49$} & 8 & 26 & 9.00 \\
\hline & 9 & 29 & 10.00 \\
\hline & 10 & 30 & 10.50 \\
\hline & 11 & 34 & 11.00 \\
\hline & 12 & 38 & 13.00 \\
\hline & 13 & 39 & 13.50 \\
\hline & 14 & 42 & 15.00 \\
\hline & 15 & 49 & 17.00 \\
\hline
\end{tabular}

Finally, we represent in Fig. 3, the vulnerability index evolution of Touares tank according to its age and its cycle life, evaluated using the nodal approximation approach. At its commissioning in 1965, the tank had a vulnerability index of $\mathrm{I}_{\mathrm{v} 0}=$ 60.50. The tank has been examined in 2014, 49 years after its commissioning and the vulnerability index found was $\mathrm{I}_{\mathrm{V}}=77.50$.
We notice an abrupt growth occurred towards the end of the study domain. This instability phenomenon, which has no physical meaning, is linked to a very large number of points $t_{i}$ (inspection dates) that give a very high degree polynomial. When we increase the order of interpolation, the polynomial may present a highly oscillatory behaviour (called Runge's phenomenon) [24] [25] that is absolutely not admissible according to the nature of the variables and the problem treated in our case (see Fig. 3).

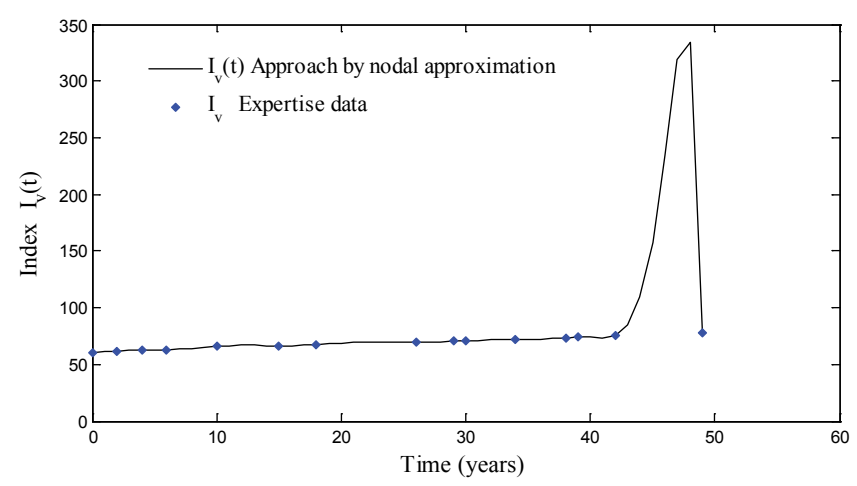

Fig. 3 Vulnerability index evolution of Touares tank

To avoid this phenomenon, we will construct the function $I_{v}(t)$ by dividing the domain into elements connected by nodes. The details of the discretization are given in the section that follows.

\subsubsection{Approach by finite element approximation}

The principle of using the approximation method is based on the possibility to master the domain of study, from the discretization in a finite number of subdomains (Fig. 4), in which the construction of the function $\Delta \mathrm{I}_{\mathrm{v}}(\mathrm{t})$ is simplified. In a first step we proceed to the construction of the approximated function $\Delta \mathrm{I}_{\mathrm{V}}(\mathrm{t})$, which is known in few points (nodes) [23]. We define in Table 7, the geometry of elements and subdomains of the study:

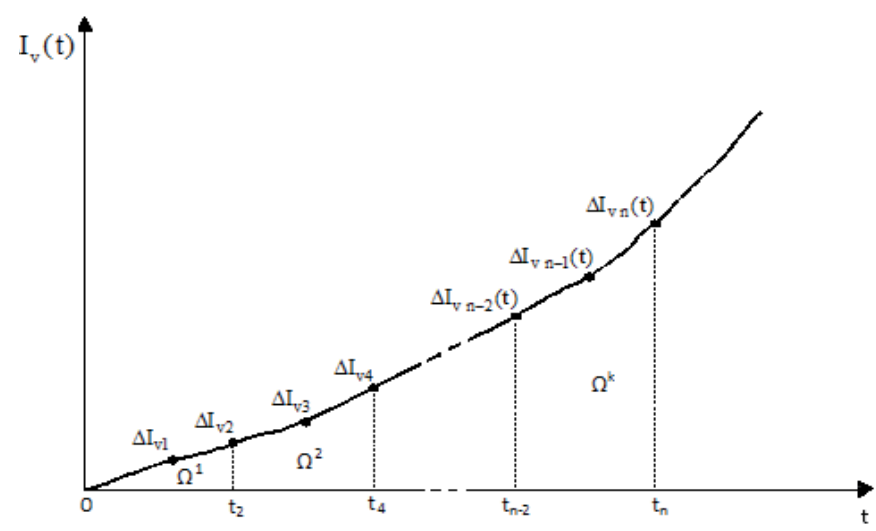

Fig. 4 Discretization in finite elements of the function in the subdomains

Table 6 Values of nodal approximation parameters $\alpha$.

\begin{tabular}{|c|c|c|c|c|c|c|c|c|c|c|c|c|c|c|c|}
\hline $\begin{array}{c}\text { Approximation } \\
\text { parameter }\end{array}$ & $\alpha_{1}$ & $\alpha_{2}$ & $\boldsymbol{\alpha}_{3}$ & $\alpha_{4}$ & $\boldsymbol{\alpha}_{5}$ & $\alpha_{6}$ & $\boldsymbol{\alpha}_{7}$ & $\alpha_{8}$ & $\alpha_{9}$ & $\alpha_{10}$ & $\alpha_{11}$ & $\alpha_{12}$ & $\alpha_{13}$ & $\alpha_{14}$ & $\alpha_{15}$ \\
\hline & 0 & -4.7 & -4.6 & 5.6 & -2.6 & 6.2 & -8.9 & -8.1 & -5 & 2.1 & -6.2 & 1.2 & -1.5 & 1.1 & 3.9 \\
\hline values & 0 & $10^{-1}$ & $10^{-1}$ & $10^{-1}$ & $10^{-1}$ & $10^{-2}$ & $10^{-3}$ & $10^{-4}$ & $10^{-5}$ & $10^{-6}$ & $10^{-8}$ & $10^{-9}$ & $10^{-11}$ & $10^{-13}$ & $10^{-1}$ \\
\hline
\end{tabular}


For the subdomain $\Omega^{1}$, the function may be approximated by a polynomial function of second degree, which can be written as [23]:

$$
\Delta I_{V}^{1}(t)=\alpha_{1}+\alpha_{2} t+\alpha_{3} t^{2}
$$

We obtain, in a matrix form:

$$
\Delta \mathrm{I}_{\mathrm{v}}^{1}(\mathrm{t})=<1, \mathrm{t}, \mathrm{t}^{2}>\left\{\begin{array}{l}
\alpha_{1} \\
\alpha_{2} \\
\alpha_{3}
\end{array}\right\}=<\mathrm{P}(\mathrm{t})>\{\alpha\}
$$

Coefficients $\alpha_{1}, \alpha_{2}$ and $\alpha_{3}$ are the approximation parameters. The approximated function $\Delta \mathrm{I}_{\mathrm{V}}{ }^{1}(\mathrm{t})$ coincides with the exact function $\Delta \mathrm{I}_{\mathrm{V}}(\mathrm{t})$ at 3 points $\mathrm{t}_{1}, \mathrm{t}_{2}$ and $\mathrm{t}_{3}$ called nodes.

We can write for the first subdomain $\Omega^{1}$.

$$
\begin{aligned}
& \Delta \mathrm{I}_{\mathrm{V}}^{1}\left(\mathrm{t}_{1}\right)=\alpha_{1}+\alpha_{2} \mathrm{t}_{1}+\alpha_{3} \mathrm{t}_{1}^{2}=\Delta \mathrm{I}_{\mathrm{V} 1} \\
& \Delta \mathrm{I}_{\mathrm{V}}^{1}\left(\mathrm{t}_{2}\right)=\alpha_{1}+\alpha_{2} \mathrm{t}_{2}+\alpha_{3} \mathrm{t}_{2}^{2}=\Delta \mathrm{I}_{\mathrm{V} 2} \\
& \Delta \mathrm{I}_{\mathrm{V}}^{1}\left(\mathrm{t}_{3}\right)=\alpha_{1}+\alpha_{2} \mathrm{t}_{3}+\alpha_{3} \mathrm{t}_{3}^{2}=\Delta \mathrm{I}_{\mathrm{V} 3}
\end{aligned}
$$

That we can rewrite in matrix form:

$$
\left[\begin{array}{lll}
1 & \mathrm{t}_{1} & \mathrm{t}_{1}^{2} \\
1 & \mathrm{t}_{2} & \mathrm{t}_{2}^{2} \\
1 & \mathrm{t}_{3} & \mathrm{t}_{3}^{2}
\end{array}\right]\left\{\begin{array}{l}
\alpha_{1} \\
\alpha_{2} \\
\alpha_{3}
\end{array}\right\}=\left\{\begin{array}{l}
\Delta \mathrm{I}_{\mathrm{v} 1} \\
\Delta \mathrm{I}_{\mathrm{v} 2} \\
\Delta \mathrm{I}_{\mathrm{v} 3}
\end{array}\right\}
$$

Or more compactly:

$$
[\mathrm{A}] \cdot\{\alpha\}=\left\{\Delta \mathrm{I}_{\mathrm{v}}\right\}
$$

Then we deduce:

$$
\{\alpha\}=[\mathrm{A}]^{-1} \cdot\left\{\Delta \mathrm{I}_{\mathrm{v}}\right\}
$$

Under another form:

$$
\left\{\begin{array}{l}
\alpha_{1} \\
\alpha_{2} \\
\alpha_{3}
\end{array}\right\}=\left[\begin{array}{ccc}
1.00 & 0.00 & 0.00 \\
-0.75 & 1.00 & -0.25 \\
0.125 & -0.25 & 2.00
\end{array}\right]\left\{\begin{array}{l}
0.00 \\
1.00 \\
2.00
\end{array}\right\}
$$

The approximated function $\Delta \mathrm{I}_{\mathrm{V}}{ }^{1}(\mathrm{t})$ for the subdomain $\Omega^{1}$ is then written:

$$
\Delta \mathrm{I}_{\mathrm{v}}^{1}(\mathrm{t})=0.50 \mathrm{t}
$$

Proceeding in the same way as for the subdomain $\Omega^{1}$, we can easily deduce approximated functions for subdomains $\Omega^{2}, \Omega^{3}$, $\Omega^{4}, \Omega^{5}, \Omega^{6}$ and $\Omega^{7}$. Then it follows the equation (17).

$$
\Delta \mathrm{I}_{\mathrm{v}}(\mathrm{t})= \begin{cases}\Delta \mathrm{I}_{\mathrm{v}}^{1}(\mathrm{t})=0.50 \mathrm{t} & \text { for } 0<\mathrm{t}<4 \\ \Delta \mathrm{I}_{\mathrm{v}}^{2}(\mathrm{t})=0.083 \mathrm{t}^{2}-0.58 \mathrm{t}+3 & \text { for } 4<\mathrm{t}<10 \\ \Delta \mathrm{I}_{\mathrm{v}}^{3}(\mathrm{t})=0.03 \mathrm{t}^{2}-0.63 \mathrm{t}+8.87 & \text { for } 10<\mathrm{t}<18 \\ \Delta \mathrm{I}_{\mathrm{v}}^{4}(\mathrm{t})=0.0075 \mathrm{t}^{2}-0.083 \mathrm{t}+6.04 & \text { for } 18<\mathrm{t}<29 \\ \Delta \mathrm{I}_{\mathrm{v}}^{5}(\mathrm{t})=-0.075 \mathrm{t}^{2}+4.92 \mathrm{t}-69.75 & \text { for } 29<\mathrm{t}<34 \\ \Delta \mathrm{I}_{\mathrm{v}}^{6}(\mathrm{t})=0.50 \mathrm{t}-6 & \text { for } 34<\mathrm{t}<39 \\ \Delta \mathrm{I}_{\mathrm{v}}^{7}(\mathrm{t})=-0.021 \mathrm{t}^{2}+2.23 \mathrm{t}-41.10 & \text { for } 39<\mathrm{t}<49\end{cases}
$$

Fig. 5 describes graphically the evolution of the vulnerability index variation with time of a tank type in Tizi Ouzou

\begin{tabular}{|c|c|c|c|c|c|}
\hline $\begin{array}{l}\text { Whole } \\
\text { domain }\end{array}$ & $\begin{array}{c}\text { Ele- } \\
\text { ments }\end{array}$ & $\begin{array}{c}\text { subdo- } \\
\text { mains }\end{array}$ & Nodes & $\begin{array}{c}\text { Nodes coordinates } \\
\text { (years) }\end{array}$ & $\Delta \mathbf{I}_{\mathrm{Vi}}$ \\
\hline & & & 1 & 0 & 0.00 \\
\hline & 1 & $\Omega^{1}$ & 2 & 2 & 1.00 \\
\hline & & & 3 & 4 & 2.00 \\
\hline & & & 3 & 4 & 2.00 \\
\hline & 2 & $\Omega^{2}$ & 4 & 6 & 2.50 \\
\hline & & & 5 & 10 & 5.50 \\
\hline & & & 5 & 10 & 5.50 \\
\hline & 3 & $\Omega^{3}$ & 6 & 15 & 6.00 \\
\hline & & & 7 & 18 & 7.00 \\
\hline & & & 7 & 18 & 7.00 \\
\hline \multirow[t]{11}{*}{$0<\mathrm{t}<49$} & 4 & $\Omega^{4}$ & 8 & 26 & 9.00 \\
\hline & & & 9 & 29 & 10.00 \\
\hline & & & 9 & 29 & 10.00 \\
\hline & 5 & $\Omega^{5}$ & 10 & 30 & 10.50 \\
\hline & & & 11 & 34 & 11.00 \\
\hline & & & 11 & 34 & 11.00 \\
\hline & 6 & $\Omega^{6}$ & 12 & 38 & 13.00 \\
\hline & & & 13 & 39 & 13.50 \\
\hline & & & 13 & 39 & 13.50 \\
\hline & 7 & $\Omega^{7}$ & 14 & 42 & 15.00 \\
\hline & & & 15 & 49 & 17.00 \\
\hline
\end{tabular}
region.

We proceed to the construction of the function $\mathrm{I}_{\mathrm{V}}(\mathrm{t})$ of each tank, which is expressed as the sum of the approximated function $\Delta \mathrm{I}_{\mathrm{v}}(\mathrm{t})$ and the vulnerability index $\mathrm{I}_{\mathrm{v} 0}$ of the tank considered at the date of commissioning, as follows:

$$
\mathrm{I}_{\mathrm{v}}(\mathrm{t})=\mathrm{I}_{\mathrm{v} 0}+\Delta \mathrm{I}_{\mathrm{v}}(\mathrm{t})
$$

Fig. 6 describes graphically the evolution of the function $I_{v}(t)$ of Touares tank.

Table 7 Identification of subdomains 


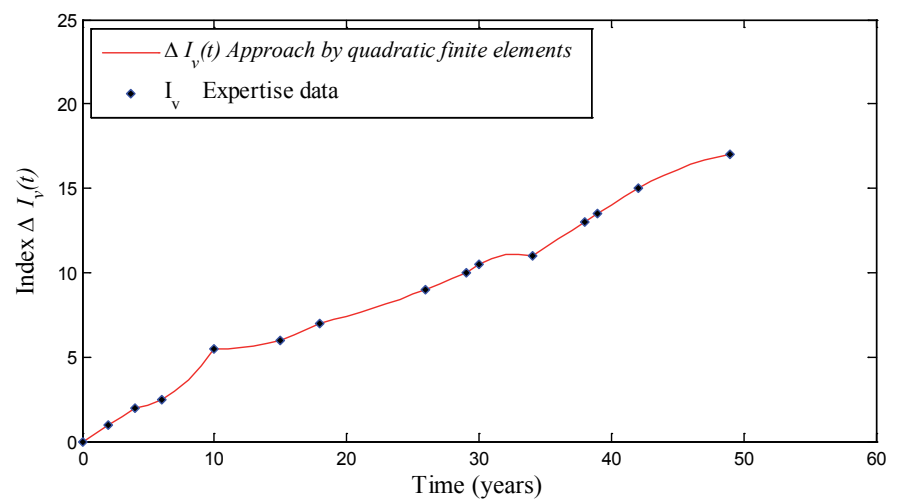

Fig. 5 Evolution of the vulnerability index variation with time of a tank type in Tizi Ouzou region

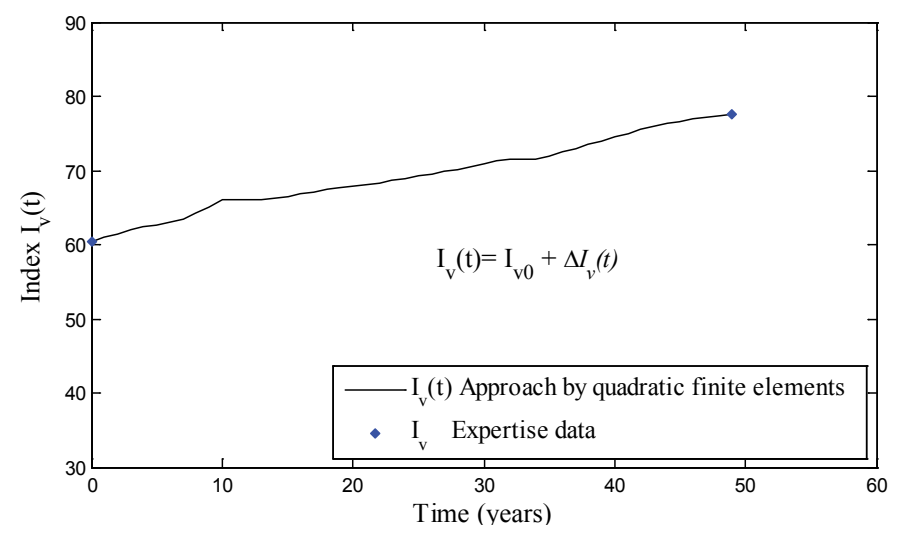

Fig. 6 Vulnerability index evolution of Touares tank

\subsection{Extrapolation model in the unknown domain}

\subsubsection{Choice of the extrapolation model}

When we proceed to the extrapolation of observed data of a phenomenon in the future, we are entitled to wonder about the choice of the model to use. Will we, guide us towards a model with an annual average rate with constant growth, called exponential model or rather towards a model that describes a constant average progression annual in absolute value called polynomial model which results in a gradual slowdown in the annual rate?

Any attempt to determine the function outside the domain of study (interpolation domain) constitutes a dangerous extrapolation which can lead to wrong and aberrant estimates, due to polynomials instability [26], because outside the domain, the function is unknown, thus not mastered. Using a polynomial model, for the extrapolation of data, only provides acceptable estimates of the evolution phenomenon in the domain where it is established, thus known.

Cremona [27] describes some degradation profiles over time of civil engineering structures based on the phenomenon studied. For example, this degradation may be linear for the corrosion phenomenon. He proposes an exponential appearance to describe the fatigue phenomenon during repeated loading as it is the case for tanks. Tanks undergo high variations of operating load (water contained in the tank), so often daily and for some three to four times a day throughout their long operating period, depending on the consumption needs of populations. Otherwise, in the case where known values allow us to imagine that past growth rhythms (in the known domain) may extend sustainably, as it is the case for the vulnerability evolution in the life cycle of a tank, it would be more reasonable to opt for an exponential model for the extrapolation of the phenomenon beyond the known domain.

\subsubsection{Approach by exponential model}

One of the main objectives of using an exponential model is the prediction of a future phenomenon from observed data. Exponential functions in their principles were used for modelling several phenomena such as the evaluation of rainfall in the field of hydrology [28], in biology [29], in economics and demography [30], in which the growth velocity is proportional to the size of the studied population.

The choice of an extrapolation of data to represent the evolution of the vulnerability index $I_{v}(t)$ with time by an exponential model is based on the hypothesis that the distribution of couples observed $\left(\mathrm{I}_{\mathrm{v}}(\mathrm{t}), \mathrm{t}\right)$ can permanently extend in view of their growth rhythm in the known domain. Based on the model of increasing number of pipe break failures in urban water distribution systems developed by Shamir and Howard [15], the exponential model assumes that the variation of a given function $\mathrm{N}(\mathrm{t})$ is described by the following differential equation:

$$
\frac{\mathrm{dN}(\mathrm{t})}{\mathrm{dt}}=\mu \cdot \mathrm{N}(\mathrm{t})
$$

Where $\mathrm{N}(\mathrm{t})$ represents the number considered at time $\mathrm{t}$ and $\mathrm{dN}(\mathrm{t})$ the density variation of the number in a time span dt. As for $\mu$, it means the growth velocity (rate coefficient) of $\mathrm{N}(\mathrm{t})$.

This last differential equation has a unique solution which can be put in the following form.

$$
N(t)=N_{0} \cdot e^{\mu \cdot t}
$$

The constant $\mu$ can be determined by assuming the initial condition $\mathrm{N}_{(\mathrm{t}=0)}=\mathrm{N}_{0}$.

The expression $\mathrm{e}^{\mu . t}$ is increasing with the growth rate evolution of the studied phenomenon at every time $t$. It is less than 1 for negative growth rates, greater than 1 for positive rates and equals 1 for a zero rate.

Equation (20) can also be written as:

$$
\ln [\mathrm{N}(\mathrm{t})]=\ln \left[\mathrm{N}_{0}\right]+\mu \cdot \mathrm{t}
$$

It comes:

$$
\mu=\frac{\ln [\mathrm{N}(\mathrm{t})]-\ln \left[\mathrm{N}_{0}\right]}{\mathrm{t}}
$$




\subsubsection{Extrapolation of the function $I_{v}(t)$}

The exponential model described in the previous section seems appropriate to describe the evolution of the vulnerability index. This model assumes that the start of the exponential growth is done abruptly without transition stage after the last subdomain (see Table 8) studied in the finite element interpolation [31]. This law can be written in the form of a differential equation as following:

$$
\frac{\mathrm{d} \Delta \mathrm{I}_{\mathrm{V}}(\mathrm{t})}{\mathrm{dt}}=\mu \cdot \Delta \mathrm{I}_{\mathrm{V}}(\mathrm{t})
$$

Where, $\mu$ represents the growth velocity of the variation of the tank vulnerability index.

To adapt the characteristics of the exponential model to the treated problem, we proceed to a variable change at the last subdomain $\Omega^{7}$ where t $€[39,49]$ as shown in the finite element approximation. To do so, we write: $\mathrm{T}=\mathrm{t}-39$.

Equation (23) becomes:

$$
\frac{\mathrm{d} \Delta \mathrm{I}_{\mathrm{V}}(\mathrm{T})}{\mathrm{dT}}=\mu \cdot \Delta \mathrm{I}_{\mathrm{v}}(\mathrm{T})
$$

The solution is on the form:

$$
\Delta \mathrm{I}_{\mathrm{V}}(\mathrm{T})=\Delta \mathrm{I}_{\mathrm{V} 39} \cdot \mathrm{e}^{\mu \mathrm{T}}
$$

Then we deduce:

$$
\mu=\frac{\ln \left[\Delta \mathrm{I}_{\mathrm{V}}(\mathrm{T})\right]-\ln \left[\Delta \mathrm{I}_{\mathrm{V} 39}\right]}{\mathrm{T}}
$$

The calculation of the coefficient $\mu$ is summarized in Table 8 .

Table 8 Evaluation of the coefficient $\mu$

\begin{tabular}{cccc}
\hline $\mathbf{t}$ (years) & $\mathbf{T}$ (years) & $\Delta \mathbf{I}_{\mathrm{vi}}$ & $\boldsymbol{\mu}$ \\
\hline 39 & 0 & 13.5 & 0.0231 \\
49 & 10 & 17 & \\
\hline
\end{tabular}

The variation of the vulnerability index studied outside the domain known is written in the form:

$$
\Delta \mathrm{I}_{\mathrm{V}}(\mathrm{T})=\Delta \mathrm{I}_{\mathrm{V} 39} \mathrm{e}^{0.0231^{*} \mathrm{~T}}
$$

Fig. 7 describes graphically the evolution of the function $\Delta \mathrm{I}_{\mathrm{V}}(\mathrm{t})$ outside the known domain by the exponential model.

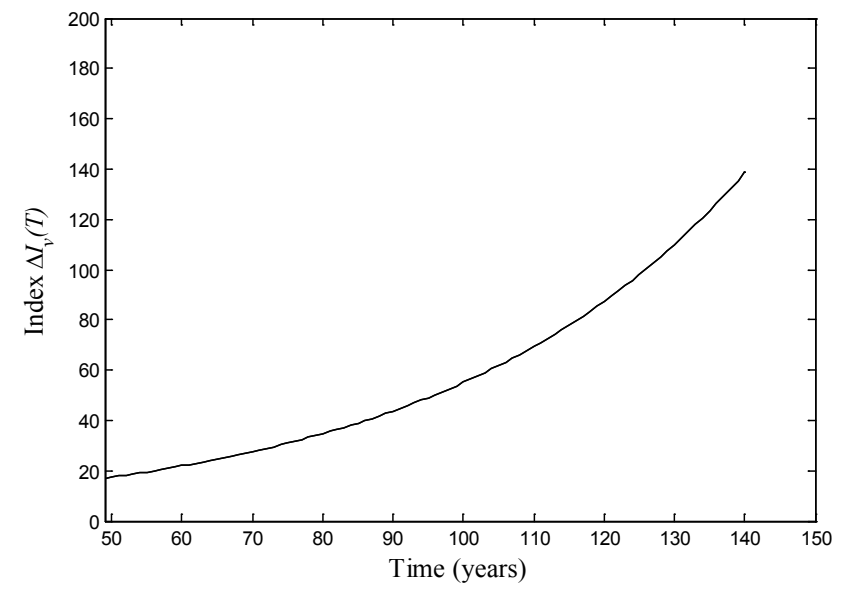

Fig. 7 Evolution of $\Delta \mathrm{I}_{\mathrm{v}}(\mathrm{t})$ by exponential model

The evolution of the vulnerability index of a tank type in Tizi Ouzou area, in its life cycle and in the unknown domain is given by the following equation:

$$
\mathrm{I}_{\mathrm{V}}(\mathrm{t})=\mathrm{I}_{\mathrm{V} 49}+\Delta \mathrm{I}_{\mathrm{V} 39} \mathrm{e}^{0.0231^{*}(\mathrm{t}-39)} \text { for } \mathrm{t}>49
$$

We resume, in what follows, the example of Touares tank, whose evolution law of the vulnerability index is approximated in the known domain by finite element approach (see Fig. 6). The evolution of its vulnerability index in the unknown domain (after the year 2014), was approximated by the exponential model, as presented above. In Fig. 8, we superpose the index evolution curve $I_{v}(t)$ of Touares tank with different levels of vulnerability that the tank can reach during its life cycle. We observe that at commissioning of this structure, it was orange level 1; it reaches the orange level 2 at 68 years and then the red level at the age of 114 years where it should be decommissioned or put in situation of restriction on use immediately. It will reach the extreme level of ruin at the age of 139 years.

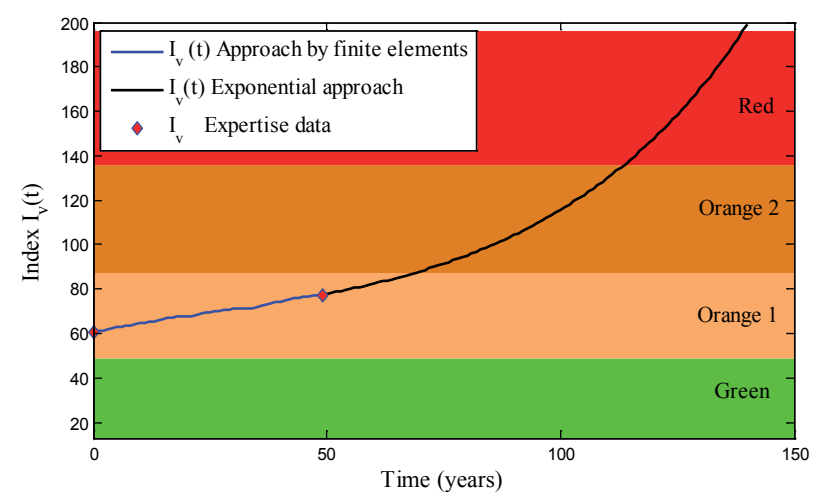

Fig. $8 \mathrm{I}_{\mathrm{v}}(\mathrm{t})$ evolution of Touares tank through the various levels of vulnerability 


\section{Validation of the model}

One of the important steps in the development and the use of a predictive model is to ensure that it is applicable in real situations. The evaluation of its performance is measured by comparing predicted values by the model, with observed values and independent of those which were used in its construction. The literature offers a wide range of methods for measuring forecast error, among which we can mention: Mean Absolute Percentage Error (MAPE) and Mean Square Error (MSE). The MSE depends on scales and it is vulnerable to outliers. The MAPE allows an overall judgment on future predictions that will be given by the predictive model, using a relative error evaluated as a percentage. This method gives the same importance to errors, contrary to the MSE method, which gives more weight to great errors compared to small errors.

For our study, this comparison will be made by calculating the measurement indicator of Mean Absolute Percentage Error (MAPE) which is the average of the absolute differences between the actual value and its forecast. This measurement considers the importance rather than the direction of forecast errors [29]. It is given by the following relation:

$$
\text { MAPE }=\left(\frac{100}{\mathrm{n}}\right) \sum_{\mathrm{i}=1}^{\mathrm{n}}\left|\frac{\mathrm{I}_{\mathrm{Vi}}^{\text {model }}-\mathrm{I}_{\mathrm{Vi}}^{\text {mesured }}}{\mathrm{I}_{\mathrm{Vi}}^{\text {mesured }}}\right|
$$

The general approach for the validation of the built predictive model can be made by two steps [32]. As a first step, we proceed to the investigation on field of some tanks which have already been examined in 2010 by Hammoum et al. [33], while choosing structures which meet the same criteria and characteristics as those used in constructing the model. In a second step, we proceed to the evaluation of MAPE. Results of these calculations are shown in Table 9.

Table 9 Evaluation of Mean Absolute Percentage Error

\begin{tabular}{clcc}
\hline Tanks & $\mathrm{I}_{\mathrm{Vi}}^{\text {model }}$ & $\mathrm{I}_{\mathrm{Vi}}^{\text {mesured }}$ & Error (\%) \\
\hline Taghanimt & 62.50 & 64.50 & 3.1007 \\
Taksebt & 48.78 & 51.50 & 5.2815 \\
Ait Halli & 66.00 & 66.50 & 0.7518 \\
SR1 Irdjen & 57.91 & 59.50 & 2.6722 \\
& & MAPE & $\mathbf{2 . 9 5 1 6}$ \\
\hline
\end{tabular}

The validation test made, on examined tanks in Tizi Ouzou region, showed that the MAPE of the vulnerability index is around $2.95 \%$. This error remains acceptable. We deduce that the constructed model demonstrated its satisfactorily ability to predict the evolution of vulnerability index to natural hazards of concrete tanks in Tizi Ouzou, in their life cycle, as presented in Fig. 9.
We are conscious that it is very difficult to have adequate data obtained in real conditions of field to validate a predictive model of vulnerability. Also, the data at the disposal of managers are often partial because obtained in a short period of observation and on a limited number of tanks. So, a better validation of this very interesting tool can only be perfected during the monitoring period that will follow after several years of operation.

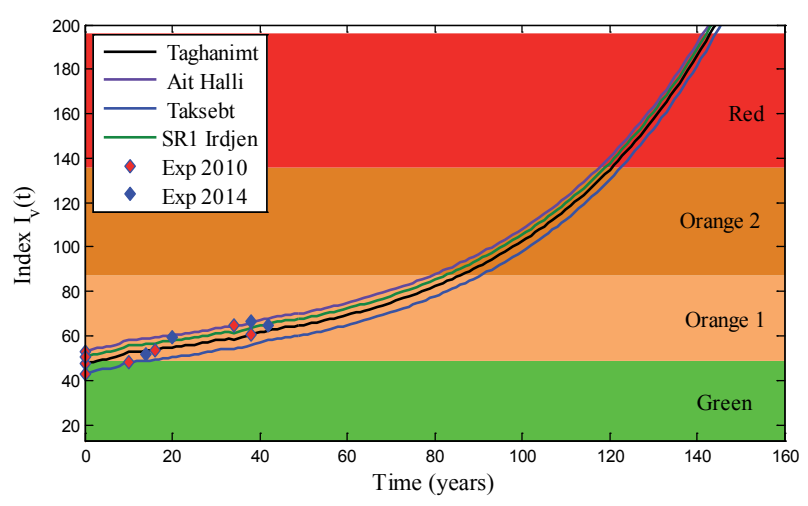

Fig. 9 Validation of the predictive model

\section{Conclusions}

The application interest of this predictive model in the context of our research resides in the precision of its results, a precision strongly related to the number of elements to which the whole domain was decomposed. This finite element approach, based on polynomial functions, allows us to discretize the whole domain into a finite number of subdomains, in order to master the domain of study with satisfactory precision. This model, in hands of managers, allows deciding on a schedule of intervention priorities in their program of rehabilitation or repairing. They will be able to predict in advance, the moment when the critical state of the tank will be reached in its life cycle and decide on the time of the service restriction or possibly its demolition. This way of doing allows to optimize the management of tanks and to plan with time financial investments sufficiently in advance, especially under significant budgetary constraints. Moreover, in the hands of engineers in design office, this model can be used at the design stage of the tank. The vulnerability index can be known and simulated at different times and therefore predict the policy management of the tank during its operation and frequency of tank monitoring. In other words, it tells us about the attention to give to the tank and the service life which coincides with the critical state of the tank reached at the red level.

The predictive model developed for tanks in Tizi Ouzou area is a good decision-making tool in the preliminary stage of expertise in the hands of expert engineers, who will have to decide on solutions to adopt for the rehabilitation or restoration of a given tank. It can be applied to other regions of Algeria, which suggests a better future for this concept of structures management. 


\section{Acknowledgement}

Authors greatly acknowledge members of the Algerian company of water distribution (Mekla, Mirabeau and Fort National agencies) for their help and documentation provided.

\section{References}

[1] Hammoum, H., Bouzelha, K., Hannachi, N. E., Serre, D. "Vulnerability assessment of the concrete tanks storage at natural hazards." In: Proceeding Concrete solutions 2011. Grantham, M., Mechtcherine, V., Schnech, U. (eds.), Taylor\&Francis Group, pp. 45-53. 2012

[2] Beer, M., Ferson, S., Kreinovich, V. "Imprecise probabilities in engineering analyses.” Mechanical Systems and Signal Processing, 37, pp. 4-29. 2013. DOI: 10.1016/j.ymssp.2013.01.024

[3] Peyras, L., Royet, P., Boissier, D. "Development of a scenario-based DSS for dam ageing diagnosis." Journal of Decision Systems. 11, pp. 445-458. 2002. DOI: 10.3166/jds.11.445-458

[4] Peyras, L., Royet, P., Boissier, D. "Dam ageing diagnosis and risk analysis: Development of methods to support expert judgement." Canadian Geotechnical Journal. 43, pp. 169-186. 2006. DOI: 10.1139/t05-096

[5] Serre, D., Peyras, L., Tourment, R., Diab, Y. "Levee performance assessment methods integrated in a GIS to support planning maintenance actions." Journal of Infrastructure System, ASCE. 14(3), pp. 201-213. 2008. DOI: 10.1061/(ASCE)1076-0342(2008)14:3(201)

[6] Serre, D., Peyras, L., Maurel, P., Tourment, R., Diab, Y. “A Spatial Decision Support System Aiding Levee Managers in their Repair and Maintenance Planning." Journal of Decision Systems. 18(3), pp. 347-373. 2009. DOI: $10.3166 /$ jds.18.347-373

[7] Bouzelha, K., Hammoum, H., Saradouni, F., Fernane, M., Lounnas, S. Vulnerability of small dams to natural hazards through a GIS. In: Proceeding IALCCE 2012, Third International Symposium on Life-Cycle and Sustainability of Civil Infrastructure Systems. Strauss, A., Frangopol, D. M., Bergmeister, K. (eds.), Taylor\&Francis Group, 2013.

[8] Boéro, J., Schoefs, F., Capra, B., Rouxel, N. "Technical management of French harbour structures - Part 1: Description of built assets." Revue Paralia. 2, 2009.

[9] Benedetti, D., Benzoni, G., Parisi, M. A. "Seismic vulnerability and risk evaluation for old urban nuclei." Earthquake Engineering and Structural Dynamics. 16(2), pp. 183-201. 1988.

[10] Mansour, A. K., Romdhane, N. B., Boukadi, N. "An inventory of buildings in the city of Tunis and an assessment of their vulnerability." Bulletin of Earthquake Engineering. 11(5), pp. 1563-1583. 2013. DOI: $10.1007 / \mathrm{s} 10518-013-9450-7$

[11] Vicente, R., Parodi, S., Lagomarsino, S., Varum, H., Mendes Silva, J. A. R. "Seismic vulnerability and risk assessment: case study of the historic city centre of Coimbra, Portugal. Bulletin of Earthquake Engineering. 9(4), pp. 1067-1096, 2011. DOI: 10.1007/s10518-010-9233-3

[12] Gent Franch, K. A., Giuliano Morbelli, G. M. G, Inostroza, M. A. A., Gori, R. E. "A seismic vulnerability index for confined masonry shear wall buildings and a relationship with the damage." Engineering Structures. 30(10), pp. 2605-2612, 2008. DOI: 10.1016/j.engstruct.2008.02.005

[13] Bezzazi, M., Khamlichi, A., Gonzalez, J. R. A. "Vulnérabilité sismique des constructions de type béton armé aux Nord du Maroc." Revue Canadienne de Génie Civil. 35(6), pp. 600-608. 2008. (in French) DOI: 10.1139/L08-010

[14] Mathieu, G. "Méthodologie d'évaluation des ouvrages hydrauliques en béton appliquée un patrimoine." Annales du BTP. 5(6), pp. 39-61. 2003.

[15] Shamir, U., Howard, C. P. D. "An analytic approach to pipe replacement." Journal of AWWA. 71(7), pp. 248-258. 1979.
[16] Andreou, S. A. "Predictive models for pipe break failures and their implications on maintenance planning strategies for deteriorating water distribution systems.” Ph.D. thesis, Massachusetts Institute of Technology, USA. 1986.

[17] Basheer, P. A. M., Chidiact, S. E., Long, A. E. "Predictive models for deterioration of concrete Structures." Construction and Building Materials. 10(1), pp. 27-37. 1996. DOI: 10.1016/0950-0618(95)00092-5

[18] Tutti, K. “Corrosion of Steel in Concrete." Swedish Cement and Concrete Research Institute, Research Report FO 4, Stockholm. 1982.

[19] Mehta, P. K. "Concrete technology at the crossroads - problems and opportunities. Concrete technology - past, present and future.” In: Mohan V, Malhotra Symposium, Kumar Mehta P (ed.), Proceeding, ACI, SP, 144, 1994.

[20] MATLAB 7.8 User's Guide, The MathWorks, Inc, USA, 2009.

[21] CGS. Algerian seismic code - RPA 2003 (DTR B-C 2-48.), Ministère de l'habitat, Algiers, 2003. (in French)

[22] CNERIB. Algerian snow and wind code - RNV 99 (DTR C 2-4.7.), Ministère de 1'Habitat, Algiers, 2000. (in French)

[23] Khenane, A. "Introduction to Finite Element Analysis Using MATLAB and Abaqus." Taylor\&Francis Group Edition, London. 2013.

[24] Boyd, J. P. "Trouble with Gegenbauer reconstruction for defeating Gibbs' phenomenon: Runge phenomenon in the diagonal limit of Gegenbauer polynomial approximations." Journal of Computational Physics. 204(1), pp. 253-264. 2004. DOI: 10.1016/j.jcp.2004.10.008

[25] Jung, J. H., Stefan, W. A. "Simple Regularization of the Polynomial Interpolation for the Resolution of the Runge Phenomenon." Journal of Scientific Computing. 46(2), pp. 225-242. 2011. DOI: $10.1007 / \mathrm{s} 10915-010-9397-7$

[26] Boyd, J. P., Ong, J. R. "Exponentially-convergent strategies for defeating the Runge Phenomenon for the approximation of non-periodic functions, part two: Multi-interval polynomial schemes and multidomain Chebyshev interpolation." Applied Numerical Mathematics. 61(4), pp. 460-472. 2011. DOI: 10.1016/j.apnum.2010.11.010

[27] Cremona, C. "Structural performance : probability-based assessmen." John Wiley \& Sons Ed., Hoboken, USA. 2011.

[28] Peng, S., Xueyuan, Q., Xi, C., Mi, Z., Simin, Q., Xinxin, M., Zhicai, Z. "Spatial distribution and temporal trends in daily and monthly precipitation concentration indices in the upper reaches of the Huai River, China." Stochastic Environmental Research and Risk Assessment. 28(2), pp. 201212. 2013. DOI: 10.1007/s00477-013-0740-z

[29] Zhou, J., Xu, Z., Chen, S. "Simulation and prediction of the thuringiensin abiotic degradation processes in aqueous solution by a radius basis function neural network model." Chemosphere. 91(4), pp. 442-447. 2013. DOI: 10.1016/j.chemosphere.2012.11.062

[30] Yusuf, F., Martins, J. M., Swanson, D. A. "Methods of Demographic Analysis." Springer Dordrecht Heidelberg edition, London, 2014.

[31] Sanna, M. "Microbiologie prévisionnelle : principaux modèles de croissance utilisés en appréciation quantitative des risques." Epidémiol. et Santé Anim. 41, pp. 169-177. 2002. (in French)

[32] Giffel, M. C., Zwietering, M. H. "Validation of predictive models describing the growth of Listeria monocytogenes." International Journal of Food Microbiology. 46(2), pp. 135-149. 1999. DOI: 10.1016/S0168-1605(98)00189-5

[33] Hammoum, H., Bouzelha, K., Bouhadoun, D., Belkacem, F. Assessment of vulnerability to natural hazards of concrete tanks in Geographical Information System. In: Proceeding. Annual Conference of the Canadian Society for Civil Engineering, Curran Associates Editor, New York, 2011. 


\section{Appendix}

Vulnerability index evolution of the inspected tanks in Tizi Ouzou

\begin{tabular}{|c|c|c|c|c|c|c|c|c|c|}
\hline $\mathbf{N}^{\circ}$ & Place called & $\begin{array}{c}\text { Capacity } \\
\left(\mathbf{m}^{3}\right)\end{array}$ & $\begin{array}{c}\text { Date of } \\
\text { commissioning }\end{array}$ & Expertise & Age & $\mathbf{I}_{\mathrm{v} 0}$ & $\mathbf{I}_{\mathrm{vi}}$ & Type of soil & Type of $\operatorname{tank}$ \\
\hline 1 & Irdjen $\mathrm{SR}_{3}$ & 1000 & 1994 & 2010 & 16 & 49.0 & 52.5 & Firm & On ground \\
\hline 2 & Tamazirth 1 & 500 & 1976 & 2010 & 34 & 44.0 & 57.0 & Bedrock & Semi underground \\
\hline 3 & Tamazirth 2 & 200 & 2003 & 2010 & 7 & 44.5 & 49.5 & Bedrock & On ground \\
\hline 4 & Taghanimt & 100 & 1972 & 2010 & 38 & 47.5 & 60.5 & Firm & On ground \\
\hline 5 & Ait Halli & 100 & 1976 & 2010 & 34 & 53.0 & 64.5 & Loose soil & On ground \\
\hline 6 & Adeni & 150 & 1976 & 2010 & 34 & 50.0 & 60.5 & Firm & Semi underground \\
\hline 7 & Ait Yacoub & 150 & 1976 & 2010 & 34 & 42.0 & 53.0 & Bedrock & Semi underground \\
\hline 8 & Ait Hague & 100 & 1976 & 2010 & 34 & 45.5 & 53.0 & Firm & Semi underground \\
\hline 9 & Mestiga & 50 & 1974 & 2010 & 36 & 46.5 & 57.5 & Firm & Semi underground \\
\hline 10 & Boudjellil & 500 & 1993 & 2010 & 17 & 44.5 & 52.0 & Bedrock & On ground \\
\hline 11 & Ibahlal & 500 & 1993 & 2010 & 17 & 47.0 & 58.5 & Firm & On ground \\
\hline 12 & Mehriz & 100 & 2002 & 2010 & 8 & 46.5 & 51.5 & Bedrock & On ground \\
\hline 13 & Irdjen $\mathrm{SR}_{1}$ & 1000 & 1994 & 2010 & 16 & 50.5 & 53.5 & Firm & On ground \\
\hline 14 & Irdjen $\mathrm{SR}_{2}$ & 1000 & 1994 & 2010 & 16 & 51.0 & 52.0 & Firm & On ground \\
\hline 15 & Taksebt & 500 & 2000 & 2010 & 10 & 43.0 & 48.5 & Bedrock & On ground \\
\hline 16 & Monobloc 1 & 500 & 2001 & 2010 & 9 & 52.0 & 52.0 & Loose soil & On ground \\
\hline 17 & Monobloc 2 & 500 & 2001 & 2010 & 9 & 51.0 & 52.0 & Loose soil & On ground \\
\hline 18 & Tansaout & 500 & 1992 & 2010 & 18 & 45.5 & 48.5 & Bedrock & On ground \\
\hline 19 & Zone Industrielle & $2 \mathrm{X} 1500$ & 1972 & 2010 & 38 & 58.0 & 79.0 & Loose soil & On ground \\
\hline 20 & Behalil 2 & 200 & 2010 & 2014 & 4 & 48.0 & 48.0 & Firm & On ground \\
\hline 21 & Behalil 1 & 100 & 1996 & 2014 & 18 & 46.0 & 53.0 & Firm & On ground \\
\hline 22 & Touares & 1000 & 1965 & 2014 & 49 & 60.5 & 77.5 & Loose soil & On ground \\
\hline 23 & Touares & 1000 & 1980 & 2014 & 34 & 61.0 & 72.0 & Loose soil & On ground \\
\hline 24 & Megdoule 2 & 500 & 2008 & 2014 & 6 & 45.0 & 49.5 & Bedrock & On ground \\
\hline 25 & Mouldiouane Village & 100 & 1988 & 2014 & 26 & 52,0 & 75.5 & Loose soil & On ground \\
\hline 26 & Herrouka 1 & 500 & 1972 & 2014 & 42 & 48.5 & 63.5 & Bedrock & On ground \\
\hline 27 & Herrouka 2 & 100 & 1984 & 2014 & 30 & 46.0 & 56.5 & Bedrock & On ground \\
\hline 28 & Megdoule1 & 500 & 2008 & 2014 & 6 & 54.0 & 56.5 & Firm & On ground \\
\hline 29 & Mennacera & 100 & 2008 & 2014 & 6 & 44.5 & 47.5 & Bedrock & On ground \\
\hline 30 & Adjaba & 250 & 1973 & 2014 & 41 & 44.5 & 63,5 & Bedrock & On ground \\
\hline 31 & Avarrane 1 & 500 & 1972 & 2014 & 42 & 56.5 & 75.5 & Loose soil & On ground \\
\hline 32 & Avarrane 2 & 1500 & 2011 & 2014 & 3 & 55.0 & 61.0 & Loose soil & Semi underground \\
\hline 33 & Mouldiouane Zone & 1000 & 2010 & 2014 & 4 & 49.5 & 51.5 & Firm & Semi underground \\
\hline 34 & Sidi Namane Maassal & 1000 & 1999 & 2014 & 15 & 52.5 & 64.0 & Firm & On ground \\
\hline 35 & Sidi Namane $\mathrm{SR}_{1}$ & 1000 & 1999 & 2014 & 15 & 53.5 & 59.5 & Loose soil & On ground \\
\hline 36 & Sidi Namane $\mathrm{SR}_{2}$ & 1000 & 2012 & 2014 & 2 & 53.5 & 54.5 & Loose soil & On ground \\
\hline 37 & Kaf Laagab & 200 & 1988 & 2014 & 26 & 56.0 & 65.0 & Loose soil & On ground \\
\hline 38 & Tighilt Tigarfiouine & 1000 & 1985 & 2014 & 29 & 56.0 & 66.0 & Loose soil & On ground \\
\hline 39 & Djemaa Saharidj & 1000 & 2008 & 2014 & 6 & 49.5 & 65.5 & Firm & On ground \\
\hline 40 & Djemaa Saharidj & 500 & 1975 & 2014 & 39 & 47.0 & 62.0 & Firm & Semi underground \\
\hline 41 & Mekla (Chaîb) $\mathrm{SR}_{1}$ & 500 & 1975 & 2014 & 39 & 54.5 & 71.5 & Loose soil & On ground \\
\hline 42 & Mekla Chef-Lieu SR 2 & 500 & 1975 & 2014 & 39 & 50.5 & 64.0 & Loose soil & Semi underground \\
\hline
\end{tabular}

